\title{
Tracheobronchitis signs observed on ventilation lung scintigraphy during the course of COVID-19 infection
}

\author{
Antoine Verger $^{1,2,3} \cdot$ Achraf Bahloul $^{1} \cdot$ Saifeddine Melki ${ }^{1} \cdot$ Gilles Karcher $^{1,2} \cdot$ Laetitia Imbert $^{1,2,3,4} \cdot$ Pierre-Yves Marie $^{1,2}$
}

Received: 7 April 2020 / Accepted: 22 April 2020 / Published online: 6 May 2020

(C) Springer-Verlag GmbH Germany, part of Springer Nature 2020

Ventilation/perfusion scintigraphy remains a method of choice for the diagnostic evaluation of pulmonary embolism (PE) [1], a possible complication of coronavirus disease 2019 (COVID19) [2]. We report here on lung single-photon emission computed tomography (SPECT) imaging conducted in this setting, using a whole-body CZT SPECT-CT camera (Veriton$\mathrm{CT}($ ), at 10 days from onset of symptoms (fever, dry cough, dyspnea) in a 68-year-old-male non-smoker without any previous history of lung disease, but RT-PCR test positive for COVID-19.

Ventilation images were obtained with ${ }^{99 \mathrm{~m}} \mathrm{Tc}$-labelled Technegas ${ }^{\circledR}$ and blood perfusion images with ${ }^{99 \mathrm{~m}} \mathrm{Tc}$-labelled albumin macro-aggregates. No mismatch indicative of PE was documented on SPECT images; however, peripheral parenchymal lung sequelae were identified on CT images, locally corresponding to decreased dual radiotracer uptake (green arrows).

Moreover, increased tracheobronchial tract uptake of Technegas ${ }^{\circledR}$ was observed (blue arrows), with particularly marked intensity on the proximal bronchi. Increased tracheobronchial uptake of Technegas ${ }^{\circledR}$ has previously been observed in patients with bronchitis or chronic obstructive pulmonary disease [1]. However, such uptake is uncommon in non-smoking patients without any prior history of lung disease and was particularly marked here, suggesting a

This article is part of the Topical Collection on Image of the month

Laetitia Imbert

1.imbert@chru-nancy.fr

1 Department of Nuclear Medicine, CHRU-Nancy, Nancy F-54000, France

2 Nancyclotep Imaging Platform, CHRU-Nancy, Nancy F-54000, France

3 Inserm, IADI, Université de Lorraine, Nancy F-54000, France

4 Inserm, DCAC, Université de Lorraine, Allée du Morvan, Vandœuvre-les-Nancy F-54000, France tracheobronchitis. The endothelial lining of the respiratory track is vulnerable to severe acute respiratory syndrome coronavirus 2 (SARS-CoV2) infection, due to high ACE2 receptor expression [3,4], and the present observation suggests that signs of a tracheobronchitis may be detected by lung scintigraphy in the course of COVID-19 infection. Although the mechanism is presumably not specific to the SARS-CoV2 virus, such signs might have diagnostic and therapeutic applications, especially in the absence of any previous history of pulmonary disease.

\section{Compliance with ethical standards}

Conflict of interest The authors declare that they have no conflict of interest.

Informed consent Informed consent was obtained from the participant for the procedure and for publication of images.

\section{References}

1. Bajc M, Schümichen C, Grüning T, Lindqvist A, Le Roux P-Y, Alatri A, et al. EANM guideline for ventilation/perfusion single-photon emission computed tomography (SPECT) for diagnosis of pulmonary embolism and beyond. Eur J Nucl Med Mol Imaging. 2019;46: 2429-51.

2. Poissy J, Goutay J, Caplan M, Parmentier E, Duburcq T, Lassalle F et al. Pulmonary Embolism in COVID-19 Patients: Awareness of an Increased Prevalence. Circulation. 2020 Apr 24. https://doi.org/10. 1161/CIRCULATIONAHA.120.047430.

3. Ren X, Glende J, Al-Falah M, de Vries V, Schwegmann-Wessels C, $\mathrm{Qu}$ X, et al. Analysis of ACE2 in polarized epithelial cells: surface expression and function as receptor for severe acute respiratory syndrome-associated coronavirus. J Gen Virol. 2006;87:1691-5.

4. Guo Y-R, Cao Q-D, Hong Z-S, Tan Y-Y, Chen S-D, Jin H-J, et al. The origin, transmission and clinical therapies on coronavirus disease 2019 (COVID-19) outbreak - an update on the status. Mil Med Res. 2020;7:11

Publisher's note Springer Nature remains neutral with regard to jurisdictional claims in published maps and institutional affiliations. 


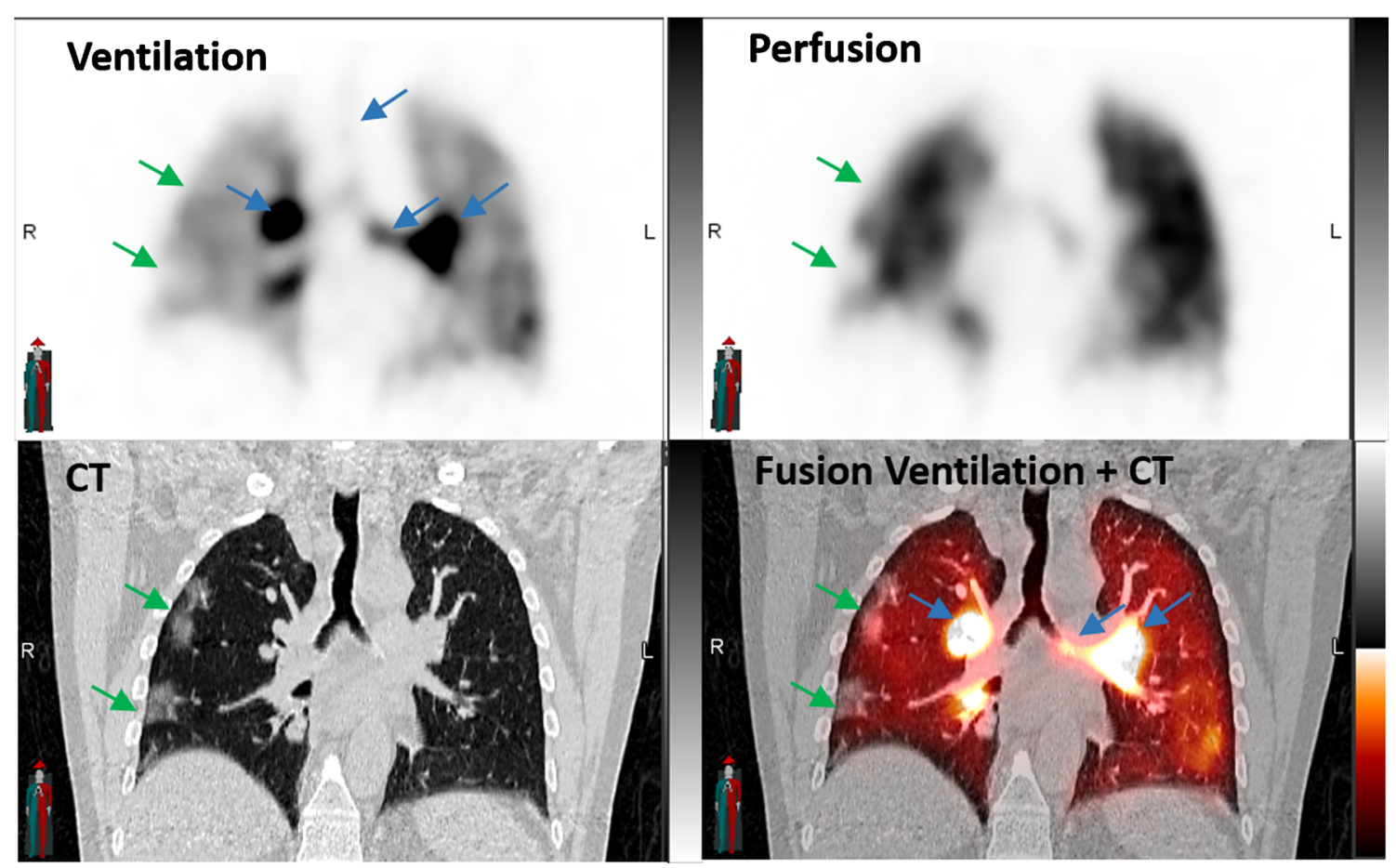

